\title{
Sociobiología y Ética
}

\author{
Javier Aldama Pinedo \\ Universidad Nacional Mayor de San Marcos \\ jaaldpe@yahoo.com
}

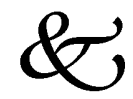

Resumen

Este artículo es una aproximación a la Sociobiología de E.O.Wilson y su interpretación de la ética. El autor empieza haciendo notar el cuestionamiento a esta disciplina, luego, sigue una secuencia cronológica que se inicia con los artículos de W.D. Hamilton sobre el comportamiento altruista, el planteamiento inicial de Wilson y ya en el plano ético con el señalamiento de dos dilemas. El artículo termina con la crítica a lo que Wilson denomina trascendentalismo.

Palabras claves: Sociobiología, Ética, Naturalismo, Filosofía de la biología, E.O. Wilson.

\section{Abstract}

This article is a study of the Sociobiology of E.O.Wilson and its interpretation of ethics, begins noting by the questioning to this discipline, then takes the common thread that has been followed: a chronological sequence that begins with the articles of W.D. Hamilton on the altruistic behavior, Wilson's initial approach, continues on the ethical field with the identification of two dilemmas, a new naturalistic interpretation of ethics, and ends with criticism of what Wilson calls: transcendentalism. Key words: Sociobiology, Ethics, Naturalism, Philosophy of biology, E.O. Wilson. 


\section{Introducción}

Una de las cosas que llama la atención en el desarrollo de la biología contemporánea es la existencia de ciertas hipótesis que en el tiempo se revaloran y se convierten en el aspecto fundamental de una teoría más amplia. Tal es el caso de la hipótesis de William D. Hamilton sobre la adecuación inclusiva (o selección parental) y la hipótesis de V.C. Wynne-Edwards sobre la selección grupal; estas hipótesis se contraponen entre sí. La primera de esta hipótesis permitió el desarrollo de la Sociobiología, disciplina que pretende explicar el comportamiento social de los animales gregarios. Uno de los expositores de esta disciplina, y quien por primera vez usa el término, es Edward $\mathrm{O}$. Wilson, entomólogo norteamericano de la Universidad de Harvard que desde el primer capítulo de Sociobiology encara a la filosofía y en especial a la filosofía moral. Propone así que ha llegado el momento de retirar temporalmente la ética de manos de los filósofos a fin de "biologizarla". Wilson en el capítulo 1 de la obra mencionada ironiza sobre lo que para Camus es la única cuestión seria: el suicidio, y brinda, a cambio, una explicación neurológica, evolucionista y genetista; y, en el capítulo 27, ataca al intuicionismo ético vinculándolo al contractualismo. Observa que su punto débil es que "confía en el juicio emotivo del cerebro como si este órgano debiera se tratado como una caja negra" 1 . En trabajos posteriores, las elucubraciones éticas de Wilson irán decantándose hasta llegar a una posición a la que califica de empirista.

\subsection{La Sociobiología: una disciplina cuestionada}

Si el expositor de esta disciplina: E.O. Wilson se hubiese limitado al estudio del comportamiento social de los animales, se tendría de la misma una aceptación y una calificación de disciplina científica. La calidad de ésta se convierte en problemática desde el momento que Wilson ensaya una interpretación sociobiológica del comportamiento humano y de sus manifestaciones culturales en el capítulo 27 de Sociobiology: "Man: From Sociobiology to Sociology". La crítica a esta propuesta no se hizo esperar y vino no solo del ámbito científico, sino de posiciones políticas, filosóficas y religiosas. La sociobiología ha sido considerada como determinista, reduccionista, y también como ideología ${ }^{2}$. La fuerza de la crítica ha sido tal que como el mismo Wilson reconoce: “...hay 
evolucionistas que estudian el comportamiento social pero que evitan usar el término "sociobiología” y quienes estudian psicología, pero que evitan usar el término "psicología evolucionista"”3. (Wilson and Wilson 2007:82-83).

Pero, ¿qué es la sociobiología? Presentamos a continuación tres definiciones.

Wilson la define de la siguiente manera:

"La sociobiología se define como el estudio sistemático de la base biológica de todo comportamiento social. En el presente, se enfoca sobre las sociedades animales, sus estructuras poblacionales, castas, y comunicación, junto con toda la fisiología que destaca las adaptaciones sociales. Pero la disciplina está también relacionada con el comportamiento social de los primeros hombres y los rasgos adaptativos de organización en las más primitivas sociedades humanas contemporáneas" (Wilson 2000 [1975]: 4).

Habría que añadir que Wilson ya plantea en la obra citada su proyecto de incluir en una síntesis moderna a las ciencias sociales y a las humanidades como las últimas ramas de la biología; así mismo, señala que en su obra se intenta codificar la sociobiología como una rama de la biología evolutiva y, en especial, de la biología de las poblaciones moderna. ${ }^{4}$

Sus más duros críticos en Not in Our Genes la definen así:

"La sociobiología es una explicación biológica determinista, reduccionista, de la existencia humana. Sus adherentes afirman, primero, que los detalles del presente y los arreglos del pasado social son las manifestaciones inevitables de la acción específica de los genes. Segundo, arguyen que los genes particulares que se encuentran en la base de la sociedad humana han sido seleccionados por la evolución, porque los rasgos que ellos determinan generan una mayor aptitud reproductiva en los individuos que los poseen. El atractivo académico y popular de la sociobiología fluye directamente de su simple programa reduccionista y de su afirmación que la sociedad humana como la conocemos es inevitable así como el resultado de un proceso adaptativo". (Lewontin, Rose and Kamin 1984: 236)

Esta es la definición de tres científicos socialistas: Richard Lewontin ${ }^{5}$, genetista evolucionista, marxista, colega de Wilson en Harvard; Steven Rose, neurobiólogo de la Open University de Gran Bretaña y Leon Kamin, psicólogo de la University of Cape Town de Sudáfrica del Sur. 
En tercer lugar, presentamos la definición de sociobiología humana de Bunge:

"La sociobiología humana es el intento de "biologizar" las ciencias sociales y, en particular, de reducirlas a la genética (Wilson, 1975; Dawkins, 1976). Sus dogmas fundamentales son: a) "el organismo es solamente el modo del ADN para fabricar más ADN”; b) estamos genéticamente programados para comportarnos tal como lo hacemos; c) todos los elementos sociales han sido diseñados por la selección natural para aumentar la adaptación; y, como consecuencia, d) las ciencias sociales deben ser reconstruidas como una rama de la biología. (Bunge 2004 [2003]: 182).

\subsection{La influencia de W.D. Hamilton}

¿De dónde procede la sociobiología? Existe un relativo consenso entre los biólogos en que el punto de partida se encuentra en los artículos de William Hamilton, genetista de Cambridge; el primero de ellos intitulado "The Evolution of altruistic behaviour" (1963) y que se publicó en American Naturalist. En este artículo Hamilton — contra la idea aceptada en su universidad- sostuvo que el altruismo no evolucionó para preservar a la especie, sino que, más bien, debía vincularse esta evolución con el parentesco consanguíneo; se serviría en su propuesta del coeficiente de relación genética $(r)$ definido por Sewall Wright como medida de relación genética, e incluiría en su modelo costo (c) y beneficios $(b)$ para el individuo altruista.

"En el modelo de Hamilton, la selección natural favorece el gen del altruismo siempre que $r \times b>c$. Esta fórmula se conoce en la actualidad como regla de Hamilton y se puede explicar así: para que la selección natural favorezca un gen que entraña altruismo, el costo $(c)$ del altruismo debe quedar compensado de alguna manera para el altruista (...) los beneficios o ventajas $(b)$ brindados a los parientes consanguíneos del altruista compensan el costo del acto altruista porque esos parientes pueden ser portadores también del gen en cuestión (...) De algún modo, el motor que impulsa la generosidad reside en la unidad familiar". (Dugatkin 2007 [2006]: 170-171)

Pero "The Evolution of altruistic behavior" no era sino un avance de un trabajo mayor y más detallado que recién llegó a ser publicado en dos partes, 1964: "The genetical evolution of social behaviour", por el Journal of Theoretical Biology. Uno de los árbitros de esta pu- 
blicación John Maynard Smith solicitó a Hamilton hacer modificaciones en el artículo presentado, lo que retrasó la publicación del mismo. Smith mientras tanto publicó su propio artículo: "Group selection and kin selection" en Nature. En este artículo minaba la propuesta de V.C. Wynne-Edwards, expuesta en Animal Dispersión in Relation to Social Behavior (1962), de que el comportamiento social evoluciona porque la selección natural favorece a ciertos grupos en lugar de otros, sirviéndose para sustentar su propia hipótesis de una idea que tomó "prestada" ${ }^{6}$ de Hamilton y a la que rotuló con el título de "selección por parentesco", definiéndola como "la evolución de características que favorecen la supervivencia de parientes cercanos del individuo afectado" 7 . Este hecho, que perjudicaba directamente el reconocimiento que merecía la investigación de Hamilton, generó una enemistad permanente entre ambos científicos.

La influencia que tuvieron los trabajos de Hamilton en la sociobiología fue muy fuerte; lo cual, por lo demás, ha sido reconocido por los dos sociobiólogos más famosos: E.O. Wilson y R.Dawkins. Ésta se deja observar en Sociobiology y The Selfish Gene en la medida que se hace uso de los modelos y —en especial — de la Regla de Hamilton. Curiosamente, las ideas de Hamilton solo alcanzaron su plena difusión entre científicos y público profano con los libros de Wilson y Dawkins.

\subsection{El planteamiento inicial de E.O.Wilson ${ }^{8}$}

Lo que denominamos el planteamiento inicial de Wilson se encuentra en dos libros publicados en los setenta: Sociobiology (1975) y $\mathrm{On} \mathrm{Hu-}$ man Nature (1978). El primero dio origen a acalorados debates, pronunciamientos y artículos en el ámbito académico y científico de EE.UU., y convirtió a Wilson en la bête noire de la izquierda norteamericana. El segundo libro es una versión que trata, específicamente, de la sociobiología humana y está dirigido al gran público; con esta obra ganó Wilson su primer premio Pulitzer. En esta parte, vamos a limitar nuestra exposición a Sociobiology.

La idea de la que parte Sociobiology fue concebida en una obra anterior de Wilson: The Insect Societies (1971), en la que se plantea a la sociobiología como la unión entre la entomología y la biología de la 
población. La idea de la selección parental (kin selection), como ya hemos visto, fue sugerida por W.D. Hamilton y posteriormente revalorada como un concepto clave de organización. Lo mencionado junto a una enorme cantidad de información que esperaba ser integrada hizo posible efectuar estudios confiables que evaluasen la adaptabilidad de la vida en colonia. Pero, ¿por qué tendría que estudiarse la vida social en relación a los insectos y no a los vertebrados? Dos argumentos presenta Wilson al respecto: primero, los insectos tienen la ventaja numérica frente al escaso número de especies de vertebrados; segundo, los insectos sociales obedecen a instintos rígidos, la interrelación herencia-ambiente es más fácil de observar en ellos. Sin embargo, esto no significó para Wilson quedarse en este nivel de estudio, así en el último capítulo de The Insect Societies plantea una perspectiva para conciliar a los dos grandes grupos de animales: insectos y vertebrados. El objetivo sugerido fue sistematizar los vínculos conciliantes entre termitas y chimpancés, esto se concretizó en Sociobiology; pero, además, en este trabajo se hace un primer esfuerzo para extender esta conciliación también hacia los seres humanos.

Sociobiology generó una doble respuesta; por una parte, un reconocimiento de los capítulos referidos a zoología; por otra, la pequeña parte referida al comportamiento humano generó una fuerte controversia académica en los setenta. Un primer grupo de críticas (provenientes de intelectuales marxistas) se centro en dos puntos: primero, que se planteaba un reduccionismo inapropiado, es decir, se reducía el comportamiento social humano a la biología; segundo, se establecía un determinismo genético, o sea la creencia que la naturaleza humana está fundada en nuestros genes. La respuesta de Wilson a esto es que la sociobiología no sólo hace hincapié en el reduccionismo (propio en alguna manera de toda ciencia), sino también en la síntesis y el holismo, y que las explicaciones sociobiológicas nunca han sido reduccionistas, sino interaccionistas; desde el punto de vista interaccionista se puede poner en primer lugar el desarrollo mental genómico, pero no se puede abolir la cultura. Segundo, concebir al cerebro humano como una tabula rasa y a la naturaleza humana como una indefinida mente flexible no es compatible con el planteamiento que la mente surge de una naturaleza 
humana que tiene una base genética. A esta crítica se sumó otra (proveniente de la unión de los marxistas con la Nueva Izquierda), centrada en la justicia social, si los genes prescriben la naturaleza humana, se sigue de esto que también pueden existir diferencias insalvables en las personalidades de cada ser humano. Luego, esto lleva a la justificación del racismo, el sexismo, la opresión de una clase por otras, etc. Wilson al respecto observa que a estas alturas (diciembre de 1999) la variación genética en la personalidad individual y la inteligencia han sido demostradas de modo concluyente.

Las dificultades para la expansión de la sociobiología humana o psicología evolucionista se deben no sólo a las críticas, sino a la creencia en que la cultura es el único artífice de la mente humana. Además, también se debe a la división tradicional en dos grandes ramas del conocimiento: ciencias y humanidades. La solución para Wilson es reconocer que la línea entre las grandes ramas de conocimiento no es una línea, sino una amplia banda que en su mayor parte es un inexplorado dominio que espera la investigación cooperativa de ambas partes. ${ }^{10}$

Para terminar este capítulo hemos de notar que luego de 25 años Wilson no renunció al proyecto de conciliar las ramas del conocimiento, pero con respecto a la naturaleza humana quiere dejar en claro cual es su posición:

"El significado objetivo de la naturaleza humana se puede alcanzar en la zona de frontera interdisciplinaria (se refiere a la frontera entre neurociencia cognitiva, genética humana, biología evolucionista y sociobiología). Hemos llegado a entender que la naturaleza humana no está prescrita por los genes ${ }^{11}$. Ni es la cultura universal, (...) Más bien, la naturaleza humana es las reglas epigenéticas, las regularidades heredadas del desarrollo mental. Estas reglas son las inclinaciones genéticas en la forma como nuestros sentidos perciben el mundo, el código simbólico por el cual nuestros cerebros se representan al mundo, las opciones que abrimos para nosotros mismos, y las respuestas que encontramos más fáciles y más gratificantes de hacer. (...) Muchas de estas reglas son evidentemente muy antiguas, datan de nuestros ancestros mamíferos, de millones de años atrás. Otras, como los pasos de la ontogénesis del desarrollo linguístico infantil, son exclusivamente humanos y probablemente sean solo de cientos de miles de años". (Wilson 2000 [1975]: vii-viii) 


\section{Ética}

\subsection{Dos dilemas}

On Human Nature se inicia con el planteamiento de dos dilemas que se vinculan particularmente a la ética y a la religión. El primero parte de la postulación que ninguna especie, incluida la humana, posee un propósito ulterior a los imperativos generados por su historia genética, se considera así que la mente humana está construida de tal manera que encierra interiormente esta restricción y hace sus elecciones según estos imperativos, “...el cerebro existe porque promueve la supervivencia y la multiplicación de los genes que orientan su montaje. La mente humana es un artefacto para la supervivencia y la reproducción, y la razón es solo una de sus varias técnicas" (Wilson 1978: 3).

El primer dilema lo presenta, Wilson, más bien, como una afirmación “...no tenemos un lugar particular adonde ir. La especie carece de objetivo externo a su propia naturaleza biológica”. Se infiere que no habiendo un objetivo más allá de lo que nuestra naturaleza biológica nos impele a hacer, entonces o seguimos viviendo en la ilusión que nos venden las religiones teístas o seculares (como el marxismo) o nos avocamos a un estudio científico de la naturaleza humana. Sin embargo, habría que tener en cuenta que la apuesta por las alternativas trascendentales se ha ido debilitando, lo que entraña un peligro para las mismas sociedades, pues estas alternativas han logrado canalizar las energías hacía determinados objetivos; por tanto, solo queda la opción de buscar una nueva moralidad basada en el conocimiento de la verdadera naturaleza humana y para esto se requiere diseccionar la maquinaria de la mente y estudiar la historia evolutiva humana. Si esto se produjese, entonces se presentaría el segundo dilema que consiste en la elección entre premisas éticas inherentes a la naturaleza biológica humana, debido a que "censores innatos y motivadores existen en el cerebro que profunda e inconscientemente afectan nuestras premisas éticas, desde esas raíces la moralidad evolucionó como un instinto" (Wilson 1978: 5).

En esencia, el segundo dilema consiste en elegir qué censores y motivadores deberán ser obedecidos y cuáles deberán, más bien, ser acortados o sublimados. En el futuro, se tendrá que decidir sobre cómo quisiéramos que siga siendo el ser humano, se elegirá conscientemente entre las alternativas de las guías emocionales heredadas. 


\subsection{Una nueva ética evolucionista}

Consciente del fracaso de vincular ética y evolución, tal como lo había hecho Herberth Spencer en el siglo XIX, Wilson ${ }^{12}$ y Ruse pretenden plantear la relación ética-evolución sobre una nueva base y para ello parten de dos proposiciones: primero, el comportamiento social de los animales está bajo control de los genes y está de tal manera estructurado que proporciona ventajas reproductivas; segundo, los humanos son animales, genéticamente somos una especie hermana de los chimpancés. Esto lleva al planteamiento de que el sentido moral humano tiene un fundamento biológico. Hay que notar al respecto que el individuo biológico coopera con sus congéneres en interés propio y que también hay una cierta conducta altruista, entendida como auto sacrificio para beneficio de otros, pero si esos otros son parientes, entonces - en el fondo- se está favoreciendo a genes idénticos a los propios, ¿qué senda ha seguido la evolución humana que la ha conducido a un cierto tipo de conducta altruista?

Los seres humanos no han seguido ni la senda económica, rígida y marcadamente altruista de las hormigas ni tampoco la hipotética senda egoísta de los súper cerebros que siempre evalúan la mejor alternativa favorable a sus propios intereses. El rumbo seguido es el que ha renunciado a la omnipotencia por la utilidad, como aquellas máquinas de ajedrez que han logrado vencer a los grandes maestros mediante ciertas estrategias que han probado ser exitosas. La mente humana no es una tabula rasa sino está moldeada de acuerdo a disposiciones innatas: las reglas epigenéticas. De éstas las mejor estudiadas son las referidas al temor y a la evitación del incesto, y aunque el caso del altruismo esté menos documentado, proponen Wilson y Ruse que se trataría de un comportamiento de adaptación, en especial si se vincula a la familia y a los aliados: necesitamos ser altruistas ${ }^{13}$.

“...La pregunta clave es entonces: ¿cómo se expresan estas reglas en nuestra conciencia intencional? Necesitamos algo para espolearnos contra nuestras disposiciones egoístas usuales. La naturaleza, por tanto, nos ha hecho (vía las reglas) creer en un desinteresado código moral, de acuerdo con el cual debemos ayudar a nuestros congéneres. En resumen, para hacernos altruistas en el sentido biológico de adaptación, nuestra biología 
nos hace altruistas en el más convencional sentido que se entiende de actuar basado en profundas creencias sobre lo correcto e incorrecto." (Ruse 1978: 315)

La crítica al antiguo darvinismo social es que solo contemplaba un aspecto del proceso de selección natural: la vida como lucha sin fin, pero ignoraba otro aspecto del mismo proceso: el altruismo y la reciprocidad en grupos altamente socializados. La especie humana ha desarrollado genuinos sentimientos de obligación, inconscientemente realizamos nuestros fines biológicos, actuamos mejor porque creemos que es correcto. "En este sentido, la evolución es consistente con los puntos de vista convencionales de la ética” (Ruse 1978: 316).

Desde el punto de vista evolucionista contemporáneo, ninguna justificación del tipo tradicional es posible. Nuestra creencia en la moralidad se refiere a una adaptación que nos permite ir más allá de nuestros fines reproductivos. La ética es una ilusión blindada por nuestros genes para lograr que cooperemos. "Es sin fundamento externo. La ética es producida por la evolución pero no justificada por esta, porque,..., sirve a un poderoso propósito sin existir en sustancia." (Ibíd.) Pero se trata de una ilusión compartida, por esto es que funciona, estamos vinculados al "juego ético" pues nuestras mentes operan según las reglas epigenéticas que discriminan las exigencias morales de las que no lo son.

Los códigos morales funcionan porque favorecen al grupo sobreviviente, a la armonía interna y, reprimen nuestros impulsos egoístas, permitiendo la multiplicación de nuestros genes. "Además, la manera que nuestra biología hace valer sus fines es haciéndonos pensar que hay un gran código objetivo, al cual estamos todos sujetos. Si pensamos que la ética no es más que una cuestión de deseos personales, tenderíamos a ignorarla. Porque pensamos que la ética está fundada objetivamente, estamos inclinados a obedecer las reglas morales...”. (Ibíd.)

Lo expuesto aporta, según Wilson y Ruse, una nueva fundamentación a la ética, ajena a la guía divina o a imperativos morales puros. Se podría, sin embargo, objetar que aunque la ética pudiese ser explicada de manera materialista, aún no se eliminaría la posibilidad de los imperativos morales, así como se puede plantear verdades matemáticas aparte de lo natural, la réplica a esta objeción es que los casos de principios matemáticos, objetos materiales y ética no son paralelos. Si los pri- 
mates no hubiesen evolucionado en las sabanas, sencillamente nuestras reglas epigenéticas serían diferentes, se exaltarían otro tipo de actos.

"La ética no tiene la fundación objetiva que nuestra biología nos lleva a pensar que tiene. Pero esta no es una conclusión negativa. Los seres humanos enfrentan increíbles problemas sociales, sobretodo porque su biología no puede arreglárselas con los efectos de su tecnología. Un más profundo entendimiento de esta biología es seguramente un primer paso hacia la solución de algunas de estas apremiantes preocupaciones. Ver la moralidad tal como es, un legado de la evolución más que un reflejo de verdades eternas inspiradas por la divinidad, es parte de este entendimiento" (Ruse 1998: 317).

\subsection{Crítica al trascendentalismo}

En Consilience, Wilson plantea una posición propia en ética y religión a la que denomina "empirismo", en el sentido que parte de los hechos (reales o supuestos), y la opone a lo que denomina "trascendentalismo", término inapropiado por la extensión que se le asigna y que incluye a cualquier fundamentación no naturalista; las posturas calificadas de trascendentalistas pueden ser teístas o seculares. Como ejemplos de estas últimas presenta Wilson las éticas de I. Kant. G.E. Moore y J. Rawls. Kant es trascendentalista (1) por plantear un poder de autodeterminación independiente de cualquier coerción de los impulsos sensibles, (2) por pretender sujetar nuestras mentes en la realización de los actos morales al imperativo categórico y, sobre todo, (3) por sostener que el "deber ser" no tiene lugar en la naturaleza y que, por tanto, la elección moral es asunto de la libre voluntad, de esta manera las criaturas racionales trascienden el reino de la naturaleza y entran al reino de la libertad. En el caso de Moore, la crítica se centra en la oposición que este muestra en Principia Ethica al naturalismo, esto es, la imposibilidad de poder fundamentar la ética en ciencias como la psicología o las ciencias sociales. Dicho sea de paso Moore fue un opositor declarado de la ética evolucionista (esto no lo menciona Wilson); pero, en especial, lo más criticable que encuentra en P.E. es la presentación de la falacia naturalista, sobre este punto volveremos más adelante. A Rawls lo cuestiona por plantear una premisa: la justicia definida como imparcialidad, la misma que es aceptada como un bien intrínseco y un imperativo, pero que no evidencia que la definición que se brinda sea consistente con la naturaleza humana. 
Ciertamente, Wilson se desplaza por el campo de la filosofía con la delicadeza de un elefante paseando dentro de una vidriería. Si presentamos sus opiniones al respecto es para que se tenga una imagen más amplia de su posición. Lo valioso en los trabajos de Wilson no está en sus críticas a los filósofos, sino en su intento por fundamentar la ética sobre bases naturales o materiales.

Pero, volvamos al asunto de la falacia naturalista, la falacia en la que se incurre cuando se pretende pasar de "lo que es" a "lo que debe ser", presentada de esta manera fue resultado de una observación de Hume ${ }^{14}$. Moore utiliza el término, pero para hacer notar que se incurre en esta falacia cuando se pretende definir lo bueno ${ }^{15}$, pues considera que bueno es indefinible, v.g, cuando se sostiene que lo bueno es lo placentero. Todo lo que se puede decir de bueno para Moore es una tautología: bueno es bueno $^{\mathrm{p}}$; sin embargo, que bueno sea indefinible no significa que sea incognoscible, se lo conoce intuitivamente, así como conocemos amarillo, aunque no podamos definirlo. Para Wilson recurrir a este razonamiento ético es incurrir en un procedimiento falaz, dicho en otras palabras, es correcto pasar de "lo que es" a "lo que debe ser".

“...El punto de vista empirista concede que los códigos morales están diseñados para conformar ciertas conductas de la naturaleza humana y para suprimir otras. Deber ser no es la traducción de la naturaleza humana sino de la voluntad pública, la cual puede hacerse cada vez más sabia y estable a través del entendimiento y las necesidades de la naturaleza humana. Reconoce que la fuerza del compromiso puede menguar como resultado de nuevos conocimientos y experiencias...

Si el punto de vista empirista del mundo es correcto, deber ser es solo taquigrafía de un tipo de afirmación fáctica, una palabra que denota lo que la sociedad primero elige (o en lo que estaba preocupada) hacer, y luego codifica. La falacia naturalista se reduce por tanto al dilema naturalista. La solución del dilema no es difícil. Esta es que deber ser es el producto de un proceso material. La solución señala el camino hacia una comprensión objetiva del origen de la ética" (Wilson 1998:251).

\section{Consideraciones finales}

- El planteamiento sociobiológico de E.O. Wilson importa a la filosofía porque cuestiona su utilidad, hace notar que la filosofía, frecuentemente, tiene una lógica propia que es ajena a lo que constituye la base natural o material de los fenómenos. 
- La explicación sociobiológica del comportamiento humano cae en el reduccionismo, es decir, intenta interpretar los fenómenos complejos del comportamiento sobre la base de la historia evolutiva de la especie y reglas epigenéticas.

- La explicación sociobiológica del comportamiento humano es determinista, Wilson usa una expresión en On Human Nature que ilustra bien este aspecto: "Los genes sujetan a la cultura de una correa". Es decir, nuestros genes, nuestro sistema nervioso y las reglas epigenéticas que lo dirigen están orientados a la supervivencia y a la reproducción de nuestros genes, entonces toda forma de cultura estaría diseñada hacia aquello que tiende al desarrollo de la vida y a una mejor adaptación al medio. Sin embargo, es fácil encontrar varios contraejemplos que más bien muestran lo contrario, es decir, hay conductas perjudiciales al grupo que las practica e incluso hay conductas claramente destructivas. Wilson, además, es determinista en otro sentido: apuesta porque en el futuro se diseñe una forma de comportamiento deseable del hombre.

- La sociobiología debido a su reduccionismo descuida las diferencias del desarrollo material según niveles. En el desarrollo que exhibe el mundo natural no es adecuado buscar explicar todo desde un nivel o desde algunos niveles básicos (física, química, biología, etc.), esto más bien empobrece la explicación; una silla (para usar un ejemplo de B. Russell) es un conjunto de átomos, pero esto le dice muy poco a un carpintero o a un decorador; del mismo modo ver el complejo comportamiento humano desde la historia evolutiva de la humanidad y reglas epigenéticas puede servir en el mejor de los casos para comprender un nivel muy básico de ciertas respuestas primarias, y en el peor ver al hombre como un primate más, ajeno a un desarrollo histórico y técnico que precisamente ha modificado su condición natural.

- Al asumir que es lícito pasar de "lo que es" a "lo que debe ser" se asume que la ética correcta o científica es aquella que conoce la naturaleza humana; además del problema lógico que esto representa, sobre la naturaleza humana se pueden presentar diferentes interpretaciones: genética, sociológica, histórica, económica, etc. Privilegiar una interpretación que se base en una ciencia o en grupo 


\section{determinado para toda circunstancia consideramos que es un error metodológico.}

\section{Notas}

1 Wilson 2000 [1975]: 562.

2 "El Grupo de Estudios Sociobiológicos del colectivo Ciencia para el Pueblo arguye que la nueva "ciencia" no tiene calidad de tal y que no es más que un puro reflejo de una forma particular de concebir las instituciones humanas". (The Ann Arbor Science for the People (1982) [1977]: 247)

3 La traducción de estas líneas (Wilson, D.S. and Wilson, E.O. 2007:328-329) es nuestra así como las siguientes traducciones que se hacen de obras publicadas en inglés. La psicología evolucionista está muy ligada a la sociobiología, el término, en este caso, se hizo de uso corriente a partir de The Adapted Mind: Evolutionary Psychology and the generation of Culture (1992), obra editada por Jerome H. Barkow, Leda Cosmides y John Tooby.

4 El porqué de la importancia de la genética de poblaciones lo explica de esta manera Michael Ruse: “...esencialmente, la genética de poblaciones da lugar a un núcleo unificado entre las distintas sub-áreas (sic) de la biología evolucionista. Por tanto, en cierto modo, cabría concebir convenientemente a la teoría evolucionista en forma semejante a la de un abanico cuyo ápice sería la genética de poblaciones”. ( Ruse, 1983 [1980]: 41)

5 Lo anecdótico en la relación Wilson-Lewontin es que fue justamente Wilson quien trajo a Harvard al camarada Dick (Vid. Segestråle 2000: 43 y ss.), como especialista en genética poblacional, uno no puede dejar de pensar — no sin cierta sorna - que si Wilson hubiese aplicado su teoría del altruismo a Lewontin se hubiese ahorrado muchos dolores de cabeza.

6 El término que utilizó Hamilton fue el de inclusive fitness (adecuación inclusiva).

7 Vid. Dugatkin 2007 [2006]: 176.

8 Hay en el pensamiento de Wilson un planteamiento inicial que se refiere a los libros que citamos, un periodo de buscar una mejor fundamentación — que se observa en los años ochenta y noventa - y un período de reconsideración que se empiezan a presentar a partir del 2005 con el artículo escrito de manera conjunta con Bert Hölldobler: "The rise of the ants: A phylogenetic and ecological explanation” ( PNAS, vol.102, no.21, May 24, 2005). Incluso Wilson ha pasado a reconsiderar el fundamento de su primer planteamiento: la selección parental, inclinándose ahora, más bien, por la selección grupal. Vid. el artículo escrito con David Sloan Wilson: "Rethinking the Theoretical Foundation of Sociobiology" en The Quarterly Review of Biology, Vol. 82. No. 4, December 2007 y el artículo: "One Giant Leap: How Insects Achieved Altruism and Colonial Life" en BioScience. Vol. 58 No.1, January 2008.

9 Vid. "Sociobiology at Century's End" en Wilson 2000 [1975]: (v)-vi.

10 Estas críticas las presenta Wilson en "Sociobiology at Century's End” y de una manera más detallada en Lumsden Ch.J y Wilson E.O.1985 [1983], Cap.II , en este trabajo Wilson anota que el primer grupo de críticas (La primera controversia sociobiológica) fue realizado por el Grupo de Estudios Sociobiológicos de la Ciencia para el Pueblo, grupo en el que figuraban cuatro colegas de Harvard; la crítica se centró en las implicancias políticas que conllevaba la sociobiología, considerada como un nuevo intento de establecer una base biológica conducente al darwinismo social. Sin embargo, observa Wilson que el argumento fallaba porque suponía que "el descubrimiento científico debe juzgarse por sus posibles consecuencias políticas, y no por la norma de si es verdadero o falso." (p.65). El segundo grupo de críticas (La segunda controversia de la sociobiología) expuestas por sociólogos y filósofos fue más serio y, por ejemplo, arguyeron que "lo que hay de exclusivo, ricamente estructurado y más interesante en la existencia 
humana es producto de la mente consciente, siempre más allá del alcance de la investigación biológica. Las ciencias naturales nunca podrán formar una sola con las ciencias sociales y las humanidades, porque su materia y su intención son fundamentalmente distintas”. (p.70)

11 Esta posición ya es expuesta en Consilience, vid. Wilson 1998: 164 y ss.

12 Nos servimos para esta parte del artículo "The Evolution of Ethics", publicado por primera vez en New Scientist, Vol 17, Oct. 1985, pp. 50-52. Este artículo lo escribieron Wilson y el filósofo Michael Ruse; en nuestra opinión, entre los trabajos donde Wilson trata de asuntos filosóficos es el mejor fundamentado. Otro detalle a tener en cuenta en este artículo es que es posterior a Genes, Mind and Culture y Promethean Fire, de aquí la relevancia que se le asigna a las reglas epigenéticas. Vid. Ruse 1998: 313-317.

13 El tema del altruismo es tan importante en el planteamiento sociobiológico que aquí preferimos tratarlo tangencialmente, esperamos poder dedicar otro artículo solo a este tema.

14 Vid. Hume, Tratado de la naturaleza humana, III, Parte primera, Sección I: 469 (en la edición consultada por nosotros pp. 689-690).

15 Cf. Moore [1903] 1959: 9.

16 Vid. Aldama 2000: 4-6.

\section{Referencias bibliográficas}

ALDAMA PINEDO, Javier (2000). La ética teórica de G.E. Moore. Tesis para optar el grado académico de Magíster en Filosofía. Lima: UNMSM.

BUNGE, Mario (2004) [2003]. Emergencia y convergencia. Novedad cualitativa y unidad del conocimiento. Barcelona: Gedisa.

DUGATKIN, Lee Alan (2007) [2006]. Qué es el altruismo. La búsqueda científica del origen de la generosidad. Buenos Aires: Katz Editores.

HUME, David (1974) [1734]. Tratado de la naturaleza humana. Buenos Aires: Ediciones Orbis.

LEWONTIN, R.C.; ROSE, S.; KAMIN, L.S. (1984). Not in Our Genes. New York: Pantheon Books.

LUMSDEN, Charles J. y Wilson, E.O. (1985) [1983]. El fuego de Prometeo. Reflexiones sobre el origen de la mente. Fondo de Cultura Económica.

MOORE, George Edward (1959) [1903]. Principia Ethica. México: UNAM.

RUSE, Michael (Ed.) (1998). Philosophy of Biology. New York: Prometheus Books.

—. (1983) [1980]: Sociobiología. Madrid: Ediciones Cátedra.

SEGERSTRÅLE, Ullica (2000). Defenders of the Truth. The Sociobiology Debate. New York: Oxford University Press.

THE ANN ARBOR SCIENCE FOR THE PEOPLE (Ed. Collective) (1982) [1977]: La Biología como arma social. Madrid: Editorial Alhambra. 
WILSON, Edward Osborne (2000) [1975]: Sociobiology. The new synthesis. Massachusetts: The Belknap Press of Harvard University Press Cambridge.

—_. (1978): On Human Nature. Massachusetts: Harvard University Press Cambridge.

—. (1998): Consilience. The Unity of Knowledge. New York: Alfred A. Knopf. WILSON, David Sloan and WILSON E.O.: "Rethinking The Theoretical Foundation of Sociobiology". The Quarterly Review of Biology. Volume 82. N. ${ }^{\circ}$ 4. pp. 327-346. December 2007. 